\title{
Surgical strategy for Kommerell's diverticulum: Total arch replacement
}

\author{
Hiroyuki Tsukui, MD, PhD, Shigeyuki Aomi, MD, PhD, and Kenji Yamazaki, MD, PhD
}

\begin{abstract}
Objective: Kommerell's diverticulum is a rare congenital aortic arch anomaly. Various surgical techniques have been reported; however, the surgical strategy is still controversial. In our institute, total arch replacement (TAR) and anatomic reconstruction of the subclavian artery (SCA) has been selected for the treatment of Kommerell's diverticulum to release the vascular ring completely and prevent postoperative complications, including dissection, rupture, hand ischemia, and subclavian steal syndrome.
\end{abstract}

\begin{abstract}
Methods: From 2000 to 2012, 4 patients (aged 38-72 years) underwent TAR and anatomic reconstruction of the SCA for Kommerell's diverticulum. All patients had a right aortic arch with an aberrant left SCA. The indications for surgery were dysphagia and dilatation of Kommerell's diverticulum. TAR, using hypothermic cardiopulmonary bypass and circulatory arrest, was performed through a median sternotomy and right anterolateral thoracotomy. After resection of Kommerell's diverticulum, the SCA was reconstructed with a graft.
\end{abstract}

Results: No hospital deaths or major complications occurred, but a 72-year-old patient required prolonged hospitalization for respiratory failure. All patients were discharged from the hospital and were free of symptoms, rupture, dissection, hand ischemia, and subclavian steal syndrome at 5 months to 11 years postoperatively.

Conclusions: TAR is a reasonable surgical technique for Kommerell's diverticulum, because it enables the vascular ring to be completely released, preventing recurrence, rupture, and dissection. Anatomic reconstruction of the SCA was effective to prevent hand ischemia and subclavian steal syndrome. (J Thorac Cardiovasc Surg 2014;148:1423-7)

In 1936, Kommerell ${ }^{1}$ reported a case of an aberrant right subclavian artery (ARSCA) originating from the descending thoracic aorta of a left aortic arch. Kommerell's diverticulum is an aneurysm of the origin of an aberrant subclavian artery (ASCA) from the descending aorta. An ARSCA with a left aortic arch occurs in $0.4 \%$ to $2.0 \%$; however, an aberrant left subclavian artery (ALSCA) with a right aortic arch (RAA) has been less common, occurring in approximately $0.1 \%{ }^{2}$ In patients with an ARSCA with a left aortic arch, the diverticulum of the aorta is an embryologic remnant of the dorsal right fourth aortic arch, but in patients with ALSCA and a RAA, the diverticulum is an embryologic remnant of the dorsal left fourth aortic arch. The ASCA will be located behind the esophagus $(80 \%)$, between the esophagus and the trachea $(15 \%)$, or in front of the trachea $(5 \%)^{3}$ and can cause symptoms that include dysphagia, dyspnea, stridor, wheezing, cough, choking spells, recurrent pneumonia, obstructive emphysema, and chest pain. ${ }^{4}$ Most

\footnotetext{
From the Department of Cardiovascular Surgery, Tokyo Women's Medical University, Shinjuku, Tokyo, Japan.

Disclosures: Authors have nothing to disclose with regard to commercial support.

Received for publication Aug 6, 2013; revisions received Nov 5, 2013; accepted for publication Nov 13, 2013; available ahead of print Dec 22, 2013.

Address for reprints: Hiroyuki Tsukui, MD, PhD, Department of Cardiovascular

Surgery, Tokyo Women's Medical University, 8-1 Kawada Shinjuku, 162-8666,

Tokyo, Japan (E-mail: htsukui@wf7.so-net.ne.jp).

$0022-5223 / \$ 36.00$

Copyright (C) 2014 by The American Association for Thoracic Surgery

http://dx.doi.org/10.1016/j.jtcvs.2013.11.026
}

patients with ASCA will be asymptomatic; however, $6 \%$ of patients with a RAA will present with rupture and $53 \%$ with either rupture or dissection. ${ }^{5}$

A number of surgical techniques have been reported for Kommerell's diverticulum. These have included graft replacement of the ASCA and descending thoracic aneurysms with carotid-to-ASCA bypass and ligation of the SCA proximal to the origin of the vertebral artery, ${ }^{6}$ graft replacement of the descending aorta with reconstruction in situ or ligation of the ASCA, endoaneurysmorrhaphy with reconstruction of the $\mathrm{SCA},{ }^{4}$ and total arch replacement (TAR) with reconstruction of the SCA. ${ }^{8,9}$ Recently, endovascular treatment has been used as an alternative to surgical repair in selected patients. ${ }^{10-13}$

At our institute, TAR with hypothermic cardiopulmonary bypass $(\mathrm{CPB})$ and circulatory arrest and reconstruction of the SCA through a median sternotomy and right thoracotomy have been used as standard treatment of Kommerell's diverticulum. This technique enables the vascular ring to be completely released, which resolves the symptoms, decreases the risk of dissection or rupture, and prevents the development of hand ischemia and subclavian steal syndrome.

\section{METHODS}

From 2000 to 2012, 4 patients (all men, aged 38-72 years) underwent TAR for Kommerell's diverticulum. All patients had a RAA with an ALSCA. The clinical characteristics of the patients are summarized in Table 1. The preoperative symptoms were dysphagia in 2 patients and 


$$
\begin{aligned}
& \text { Abbreviations and Acronyms } \\
& \text { ALSCA }=\text { aberrant left subclavian artery } \\
& \text { ARSCA }=\text { aberrant right subclavian artery } \\
& \text { ASCA }=\text { aberrant subclavian artery } \\
& \text { CPB }=\text { cardiopulmonary bypass } \\
& \text { RAA }=\text { right aortic arch } \\
& \text { RSCA }=\text { right subclavian artery } \\
& \text { SCA }=\text { subclavian artery } \\
& \text { TAR }=\text { total arch replacement }
\end{aligned}
$$

dizziness in 1 . The remaining patient was asymptomatic. The maximum size of the aneurysm was $40 \times 80 \mathrm{~mm}$. The Tokyo Women's Medical University institutional review board approved study, and the need for patient consent was waived.

\section{Operative Technique}

The patient was placed in the supine position. The right hand was slightly deviated, and a towel pad was placed under the right scapula to keep the hemithorax elevated. Through a median sternotomy, 3 arch vessels and the distal portion of the ALSCA were exposed and taped. CPB was established by femoral artery and/or ascending aorta cannulation and bicaval drainage with a pulmonary artery vent. With the patient under deep hypothermia at a core temperature of $18^{\circ} \mathrm{C}$, circulatory arrest with retrograde cerebral perfusion was induced. The aortic arch was reconstructed in the following order: right SCA, right common carotid artery, and left common carotid artery, using the arch first technique with a quadrifurcated graft (Triplex, Terumo, Tokyo, Japan). ${ }^{14}$ After reconstruction of the arch vessels, antegrade cerebral perfusion was resumed from the side arm of the graft. A right anterolateral thoracotomy in the third, fourth, or fifth intercostal space was added, without connecting the median sternotomy, and the Kommerell's diverticulum was exposed. After crossclamping, the descending aorta was transected at the level of the azygos vein and anastomosed to the distal end of the graft. Reperfusion and rewarming were started. The distal portion of the ALSCA was

TABLE 1. Patient characteristics

\begin{tabular}{lcccc}
\hline & \multicolumn{4}{c}{ Pt. no. } \\
\cline { 2 - 5 } \multicolumn{1}{c}{ Characteristic } & $\mathbf{1}$ & $\mathbf{2}$ & $\mathbf{3}$ & $\mathbf{4}$ \\
\hline Age (y) & 57 & 55 & 72 & 38 \\
Height $(\mathrm{cm})$ & 171 & 172 & 163 & 168 \\
Weight $(\mathrm{kg})$ & 69 & 69 & 52 & 63 \\
BSA $\left(\mathrm{m}^{2}\right)$ & 1.81 & 1.55 & 1.55 & 1.72 \\
Symptoms & Dizziness & None & Dysphagia & Dysphagia \\
Hypertension & Yes & No & Yes & No \\
Hyperlipidemia & Yes & No & Yes & No \\
Diabetes & No & No & No & No \\
Cerebrovascular disease & No & No & No & No \\
Renal insufficiency & No & No & Yes & No \\
Dialysis & No & No & No & No \\
Coronary artery disease & No & No & Yes & No \\
Maximum aneurysm & 50 & 80 & 20 & 25 \\
$\quad$ size (mm) & & & & \\
Thoracotomy approach & 4 th & 5 th & 4 th & 3 rd \\
$\quad$ intercostal space & & & & \\
Length of hospital stay (d) & 50 & 55 & 291 & 26 \\
\hline
\end{tabular}

Pt. no., Patient number; BSA, body surface area. interposed with the graft and anastomosed to the graft through the median sternotomy. Finally, the graft was anastomosed to the ascending aorta (Figure 1).

\section{RESULTS}

No hospital deaths or major complications occurred; however, a 72-year-old patient required prolonged hospitalization because of respiratory failure. All patients had been discharged from hospital, and all were still alive without any symptoms 5 months to 11 years postoperatively. The mean $\mathrm{CPB}$, aortic crossclamp, and circulatory arrest time was 254.3 minutes (range, 194-306), 122.8 minutes (range, 87-163), and 47.0 minutes (range, 2668 ), respectively. No patient developed dissection or rupture after surgery. Also, no patient developed hand ischemia or subclavian steal syndrome. In a 38-year-old patient with dysphagia, a preoperative 3-dimensional computed tomography scan revealed Kommerell's diverticulum, $25 \mathrm{~mm}$ in size, that was compressing the esophagus. After TAR, the esophagus was not compressed and the dysphagia had disappeared (Figure 2). The left SCA was reconstructed with a graft.

\section{DISCUSSION}

The indications for surgical repair have not been established because the number of patients with Kommerell's diverticulum has been small. Most patients with Kommerell's diverticulum will have no symptoms; however, Austin and Wolfe ${ }^{5}$ reported that $19 \%$ of patients presented with rupture, all of whom died. Cinà and colleagues ${ }^{4}$ reviewed the published data, including 32 patients, and reported that $6 \%$ of the affected patients presented with rupture and $53 \%$ with either rupture or dissection. The size of Kommerell's diverticulum cannot be used to predict rupture because of the limited data. Cinà and colleagues ${ }^{4}$ suggested aggressive treatment of aneurysms with a diameter of $\geq 3$ $\mathrm{cm}$ in low-risk patients. Ota and colleagues ${ }^{7}$ recommended surgical repair for symptomatic aneurysms with a diameter of $\geq 5 \mathrm{~cm}$. Backer and colleagues ${ }^{15}$ suggested that

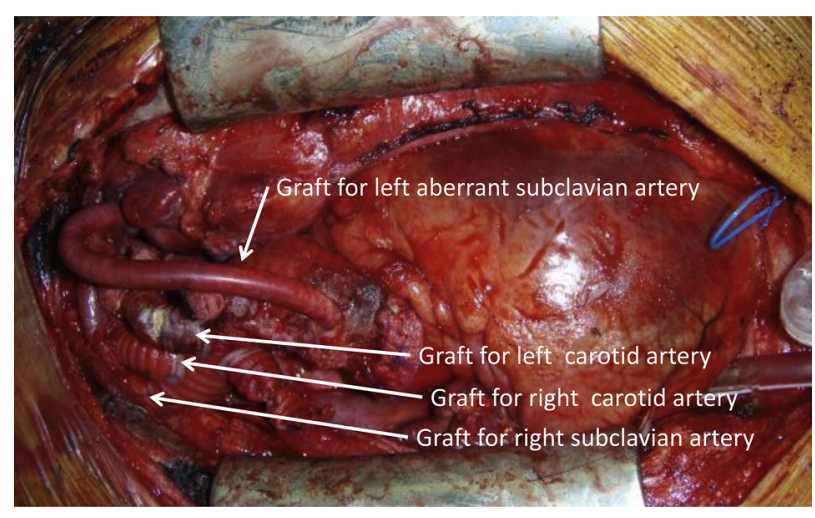

FIGURE 1. Image after repair. 

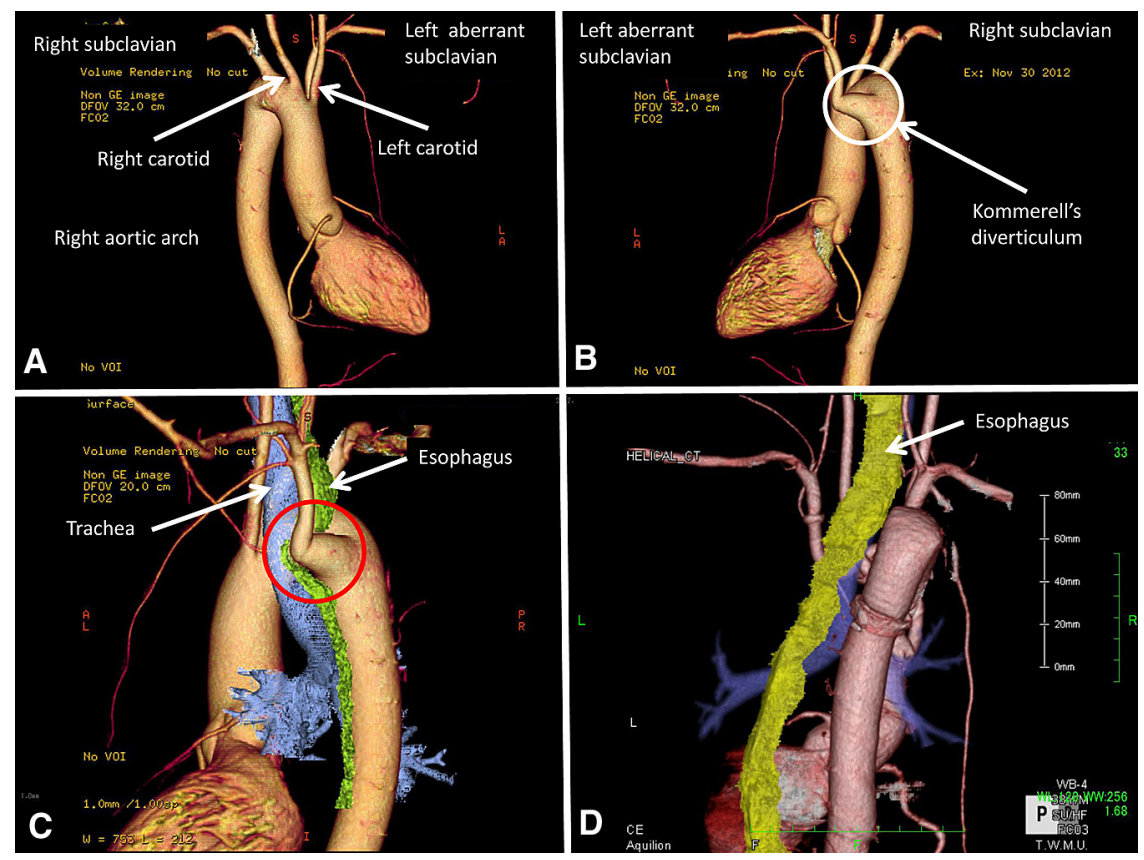

FIGURE 2. A, Preoperative 3-dimensional computed tomography (3D-CT) scan from front showing right aortic arch. B, Preoperative 3D-CT scan from rear showing Kommerell's diverticulum, $25 \mathrm{~mm}$ in size. The aberrant right subclavian artery originated from the descending aorta. C, Preoperative 3D-CT reconstruction of aorta, esophagus, and trachea demonstrating compression of the esophagus by Kommerell's diverticulum. D, Postoperative 3D-CT scan showing the absence of compression of the esophagus after surgery.

Kommerell's diverticulum in children should be resected if the diverticulum is a widening of the base of the SCA that is $>1.5$ times the diameter of the distal SCA.

A number of surgical approaches to Kommerell's diverticulum have been proposed, including median sternotomy alone, ${ }^{8}$ right thoracotomy alone, ${ }^{4,7}$ left thoracotomy alone, ${ }^{6}$ bilateral thoracotomy, ${ }^{16}$ and median sternotomy plus thoracotomy, such as we have reported. Kai and colleagues ${ }^{8}$ reported TAR for an ALSCA with a RAA through a median sternotomy alone. Kommerell's diverticulum was completely transected, and open distal anastomosis was performed with an elephant trunk technique under limited exposure. However, a distal anastomosis might be difficult to perform if Kommerell's diverticulum is located in the lower portion of the descending aorta or involves a large segment of the aorta. Our approach for the RAA using a median sternotomy plus right thoracotomy provided excellent exposure for distal anastomosis of the descending aorta through the right thoracotomy and of the aortic arch and the proximal portion of the ALSCA through the median sternotomy. However, the approach using median sternotomy plus right thoracotomy could have disadvantages, including infection, postoperative pain, and respiratory failure. One of our patients, a 72-yearold man, required prolonged hospitalization because of respiratory failure.

The management of Kommerell's diverticulum depends on its anatomy and size. Cinà and colleagues ${ }^{4}$ used endoaneurysmorrhaphy for a small Kommerell's diverticulum with a normal descending thoracic aorta and graft replacement for a large Kommerell's diverticulum or Kommerell's diverticulum associated with an aneurysm of the descending thoracic aorta. In children with a vascular ring with a RAA and ALSCA, division of the ligamentum arteriosum has been a standard operation; however, some of those patients had residual symptoms postoperatively and required reintervention. ${ }^{17,18}$ Primary resection of Kommerell's diverticulum and transfer of the ALSCA to the left carotid artery and division of the ligamentum have been recommended to eliminate residual symptoms. ${ }^{15,17-19}$ Backer and associates ${ }^{15}$ hypothesized 3 mechanisms that create tracheal and esophageal compression in patients with Kommerell's diverticulum. The first mechanism is the space-occupying effect of Kommerell's diverticulum in the mediastinum. The second mechanism is the sling-like effect of the ALSCA pulling the RAA toward the left side. This pulls the RAA against the trachea and esophagus. The third mechanism is the ALSCA acting as a "bowstring" between the descending thoracic aorta on the right side and the arm on the left side, and this alone can be enough to compress the esophagus posteriorly. The resection technique for Kommerell's diverticulum reported by Backer and colleagues ${ }^{17}$ is to place a side-biting vascular clamp on the descending aorta at the origin of the Kommerell's diverticulum and perform primary closure with sutures or apply a polytetrafluoroethylene patch if the base of the Kommerell's diverticulum is friable. However, we have hesitated to perform this technique 
in elderly patients, because they often have calcification of the aorta and have a risk of dissection with the use of a side-biting vascular clamp. Also, a small, but existent, risk of rupture owing to aneurysmal formation after surgery is present in the case of incomplete resection of Kommerell's diverticulum. Our strategy, TAR, with the patient under circulatory arrest with deep hypothermia, might be aggressive for treating Kommerell's diverticulum; however, the outcomes of TAR have improved during the past decade, even in elderly patients, with a low risk of perioperative stroke. ${ }^{20}$ Circulatory arrest with deep hypothermia eliminates the need to clamp Kommerell's diverticulum, preventing perioperative stroke and dissection. In addition, TAR enables complete resection of Kommerell's diverticulum, completely correcting the 3 mechanisms proposed by Backer and colleagues. ${ }^{15}$

Various strategies for treating ASCA have been reported. In situ reconstruction of the SCA using a graft is a simple and useful technique ${ }^{7}$; however, a risk exists of dilatation of the residual ASCA in cases of incomplete aneurysm resection due to limited exposure. Aortoesophageal fistula caused by the graft contacting the esophagus is a rare complication, but its mortality has been quite high. ${ }^{21,22}$ Carotid-to-SCA bypass ${ }^{6,23}$ or transposition of the SCA on the carotid artery ${ }^{4,23}$ through a supraclavicular incision are alternative options for patients in whom direct continuity between the descending thoracic aorta and distal SCA cannot be easily established. Kamiya and colleagues $^{23}$ reported 3 different methods for ARSCA: complete resection of the ARSCA aneurysm through a left thoracotomy after reconstruction of the RSCA through a supraclavicular approach (2-staged operation, group 1), exclusion of the ARSCA aneurysm through a left thoracotomy without reconstruction of the RSCA (group 2), and closure of the distal site of the ARSCA aneurysm through a median sternotomy plus reconstruction of the RSCA. The ARSCA aneurysm was left as a blind sack (group 3). The patients in groups 1 and 3 had excellent outcomes after surgery; however, 1 patient in group 2 developed subclavian steal syndrome because the RSCA had not been reconstructed. In group 3, resection of the ARSCA aneurysm was attempted through a median sternotomy; however, the position of the ARSCA aneurysm made it too deep to resect. A risk exists of persisting symptoms and future rupture, because the aneurysm was left as a blind sac, which was not depressurized. Other investigators reported that patients with Kommerell's diverticulum developed subclavian steal syndrome after ligation of SCA and division of the ligamentum and required carotid-to-SCA bypass later. ${ }^{24,25}$ Our surgical strategy for ASCA has been anatomic reconstruction of the SCA with a graft placed to prevent the development of ischemia and subclavian steal syndrome.

Endovascular repair has been reported for selected patients with Kommerell's diverticulum. ${ }^{10-13}$ Attmann and colleagues ${ }^{10}$ reported 2-stage surgical and endovascular treatment in a frail elderly patient with an ARSCA. Before endovascular treatment, left-sided carotid-to-SCA bypass was performed to secure the proximal landing zone. Endovascular repair is a valuable alternative to surgical repair using CPB, especially for ruptured Kommerell's diverticulum, because of the unstable hemodynamics. ${ }^{11-13}$ However, the long-term outcomes are still unknown.

\section{CONCLUSIONS}

On the basis of our experience, TAR through a median sternotomy and right thoracotomy for Kommerell's diverticulum remains the preferred method of treatment, even though it requires deep hypothermic CPB and circulatory arrest. It provides excellent exposure and enables complete resection of Kommerell's diverticulum and anatomic repair of the ASCA. This resolves the symptoms without recurrence, decreases the risk of dissection and future rupture, and prevents the development of hand ischemia and subclavian steal syndrome.

\section{References}

1. Kommerell B. Verlagerung des Oesophagus durcheine abnorm verlaufende Arteria subclavia dextra (Arteria Lusoria). Fortschr Geb Roentgenstr. 1936;54: $590-5$.

2. Freed K, Low VHS. The aberrant subclavian artery. AJR Am J Roentgenol. 1997; 168:481-4.

3. Gomes MM, Bernatz PE, Forth RJ. Arteriosclerotic aneurysm of an aberrant right subclavian artery. Dis Chest. 1968;54:549-52.

4. Cinà CS, Althani H, Pasenau J, Abouzahr L. Kommerell's diverticulum and right-sided aortic arch: a cohort study and review of the literature. J Vasc Surg. 2004;39:131-9.

5. Austin EH, Wolfe GW. Aneurysm of aberrant subclavian artery with a review of the literature. J Vasc Surg. 1985;2:571-7.

6. Kouchoukos NT, Masetti P. Aberrant subclavian artery and Kommerell aneurysm: surgical treatment with a standard approach. J Thorac Cardiovasc Surg. 2007; 133:888-92.

7. Ota T, Okada K, Takanashi S, Yamamoto S, Okita Y. Surgical treatment for Kommerell's diverticulum. J Thorac Cardiovasc Surg. 2006;131:574-8.

8. Kai M, Okabayashi H, Soga Y, Hanyu M, Nomoto T, Nakano J, et al. Total arch replacement through a midsternotomy for a right-sided aortic arch aneurysm with an aberrant left subclavian artery. J Thorac Cardiovasc Surg. 2006;132: 1473-5.

9. Yoshida S, Aomi S, Ozawa H, Maeda T, Kawai A, Nishida H, et al. Total arch replacement for right aortic arch with Kommerell diverticulum and aberrant left subclavian artery. Kyobu Geka. 2003;56:403-5.

10. Attmann T, Brandt M, Müller-Hülsbeck S, Cremer J. Two-stage surgical and endovascular treatment of an aneurysmal aberrant right subclavian (Lusoria) artery. Eur J Cardiothorac Surg. 2005;27:1125-7.

11. Kim HW, Chun HJ, Suh JH, Yoon JS. Endovascular repair of an intra-thoracic ruptured aneurysm of left subclavian artery in a patient with a right-sided aortic arch with aberrant left subclavian artery. Eur J Cardiothorac Surg. 2010;37:1233.

12. Yamashiro S, Nagano T, Kuniyoshi Y, Kise Y, Maeda T, Arakaki R. Endovascular repair of intrathoracic ruptured Kommerell's diverticulum. Asian Cardiovasc Thorac Ann. 2012;20:587-90.

13. Motoki M, Hattori K, Kato Y, Takahashi Y, Kotani S, Nishimura S, et al. Endovascular repair of ruptured aberrant left subclavian artery with right aortic arch. Ann Thorac Surg. 2013;95:699-701.

14. Tsukui H, Aomi S, Tomioka H, Nonoyama M, Koyanagi H, Nagasawa C, et al. Arch-first technique versus conventional method for aortic arch operation using branched graft. Asian Cardiovasc Thorac Ann. 2002;10:318-21.

15. Backer CL, Russell HM, Wurlitzer KC, Rastatter JC, Rigsby CK. Primary resection of Kommerell diverticulum and left subclavian artery transfer. Ann Thorac Surg. 2012;94:1612-7. 
16. Keeling WB, Kerendi F, Chen EP. Total aortic arch replacement for the treatment of Kommerell's diverticulum in a Jehovah's Witness. J Card Surg. 2010;25: 333-5.

17. Backer CL, Hillman N, Mavroudis C, Holinger LD. Resection of Kommerell's diverticulum and left subclavian artery transfer for recurrent symptoms after vascular ring division. Eur J Cardiothorac Surg. 2002:22:64-9.

18. Shinkawa T, Greenberg SB, Jaquiss RD, Imamura M. Primary translocation of aberrant left subclavian artery for children with symptomatic vascular ring. Ann Thorac Surg. 2012;93:1262-5.

19. Backer CL, Mavroudis C, Rigsby CK, Holinger LD. Trends in vascular ring surgery. J Thorac Cardiovasc Surg. 2005;129:1339-47.

20. Minatoya K, Ogino H, Matsuda H, Sasaki H, Yagihara T, Kitamura S. Surgical management of distal arch aneurysm: another approach with improved results. Ann Thorac Surg. 2006;81:1353-7.
21. Lawrie GM, Earle N, De Bakey ME. Evolution of surgical techniques for aneurysms of the descending thoracic aorta: twenty-nine years experience with 659 patients. J Card Surg. 1994;9:648-61.

22. Svensson LG, Crawford ES, Hess KR, Coselli JS, Safi HJ. Experience with 1509 patients undergoing thoracoabdominal aortic operations. J Vasc Surg. 1993; 17:357-68.

23. Kamiya H, Knobloch K, Lotz J, Bog A, Lichtenberg A, Hagl C, et al. Surgical treatment of aberrant right subclavian artery (arteria lusoria) aneurysm using three different methods. Ann Thorac Surg. 2006;82:187-90.

24. Ciocca RG, Wilkerson DK, Madson DL, Andrew CT, Graham AM. Symptomatic subclavian steal syndrome four decades after operation for dysphagia lusoria. Ann Vasc Surg. 1995;9:204-8.

25. Jung JY, Almond CH, Saab SB, Lababidi Z. Surgical repair of right aortic arch with aberrant left subclavian artery and left ligamentum arteriosum. $J$ Thorac Cardiovasc Surg. 1978;75:237-43. 